\title{
THE FAÇADE OF THE CHURCH OF NUESTRA SEÑORA DE LA ASUNCIÓN IN BIAR (SPAIN): FROM POINT CLOUD TO HBIM
}

\author{
JOSÉ ANTONIO HUESCA TORTOSA, DAVID TORREGROSA FUENTES, \\ MIGUEL LOUIS CERECEDA \& YOLANDA SPAIRANI BERRIO \\ Department of Architectural Constructions, University of Alicante, Spain
}

\begin{abstract}
Nowadays, the use of Building Information Modelling (BIM) for cultural heritage preservation is a challenging topic and its complexity increases considerably as far as the need of introducing sculptural elements integrated in façades of church doors and historical heritage buildings arises. For this aim, it is essential to control all the workflow covering data acquisition by topographic techniques, terrestrial laser scanning (TLS) or photogrammetry and the so-called Heritage Building Information Modelling (HBIM). For this purpose, the parametric modelling by BIM requires the improvement of the mesh integration of sculptural elements previously generated from point clouds by TLS. Thus, the success of the final outcome will depend in large measure on the work-flow generated with different software used for the mesh modelling and refining and its integration in the BIM model. Once sculptural elements have been integrated in the BIM model, their information implementation and the introduction of behavior and features associated become critical for the correct interpretation. In this paper, we present a survey and an analysis on the degradation of the stony elements as well as the characterization of different materials used in the construction and in the subsequent interventions and that can be observed to date of today. Focused on the façade of the Church of Nuestra Señora de la Asunción of Biar (Alicante, Spain), where a set of sculpture reliefs revolving around the main scene located at the tympanum stands out extraordinarily, and whose sculptural ensemble is severely affected by the impact of a high degree of erosion and pollution processes.
\end{abstract}

Keywords: point clouds, BIM, Building Information Modelling, cultural heritage, survey, conservation, maintenance, Biar.

\section{INTRODUCTION}

The façade of the Church of Nuestra Señora de la Asunción in Biar, authentic architectural jewel of the Valencian Community in the province of Alicante, has undergone both the passage of time and the nature of its stone structure. They have been complicit in its deterioration and responsible for the delicate state in which it is at present, such as many works of our heritage have also undergone.

This façade is located in the city of Biar, Alicante, former border town and royal villa since 1287, has its enormous importance because it is the first Renaissance main front in the province of Alicante. From the beginning of the 16th century, between the Late Gothic and the first reminiscences of the Italian Renaissance, it is a representation of the typical Valencian renaissance. Experts and illustrious historians and architects date their construction from 1519, but it is actually from the day of the Assumption of the Virgin Mary (August 15th and Friday) of that year when there is faith of the commitment of execution on the part of the "mestre pedrapiquer" from the drawing done by the "mestre pintor" and in which will not start working until the day of San Miguel (September 29th and Monday).

The composition of the main front, with its two bodies arranged by double pilasters to the sides, the division of the heights by means of entablatures, its door inlet, its tympanum with semicircular arches, its moved trapezoidal plant and its accentuated flare demonstrates both a rapprochement to a classic lexicon as the whole organizational structure proper to Gothic structures. 


\section{STATE OF THE ART}

The essence of this work is the interpretation and correspondence between what it has been drawn and the existing reality. Thus, the main objective of this work is to get the workflow to obtain the graphic survey as accurate as possible for implementing in BIM models [1]-[3]. The existing techniques and tools allow the faithful recreation of reality and with greater accuracy, not only in its materialization as architectural plans but also as a tool for the diagnosis and interpretation of the deformations and problems that the element or architecture can have to study [4], [5]. The implementation of models with the "as built" information (BIM) together with the tools of the exact recreation of the reality form a very interesting tandem for its development within the performance in the existing architecture and intervention in the built heritage [6].

\section{THE TERRESTRIAL LASER SCANNER SURVEY}

Due to the number and complexity of sculptural elements that make up this façade, the use of terrestrial LIDAR (Light Detection and Ranging) technology is used by means of a highprecision terrestrial laser scanner (TLS) for data acquisition, and virtualization in three dimensions.

The laser scanner used is based on time-of-flight of a pulsed laser (Leica model ScanStation C10), which measures through a laser beam generating a point cloud of the scanned element with a maximum density of one point every $2 \mathrm{~mm}$ of distance, a complete field of view of $360^{\circ}$ in horizontal by $270^{\circ}$ in vertical, and a long reach (until $300 \mathrm{~m}$.). Photographs are also obtained from both the internal camera of the scanner and a SLR camera adapted to the same scanner to give the real chromatism of the scanned element to the point cloud (Fig. 1).

The data presented for this study correspond to the last field work carried out during the month of March 2017 (phase 3) of the last three years (from 2014 to 2017), and in order to complete the follow-up and control over the possible erosion and deterioration of the main front. The stations and the study area can be observed in Fig. 2.

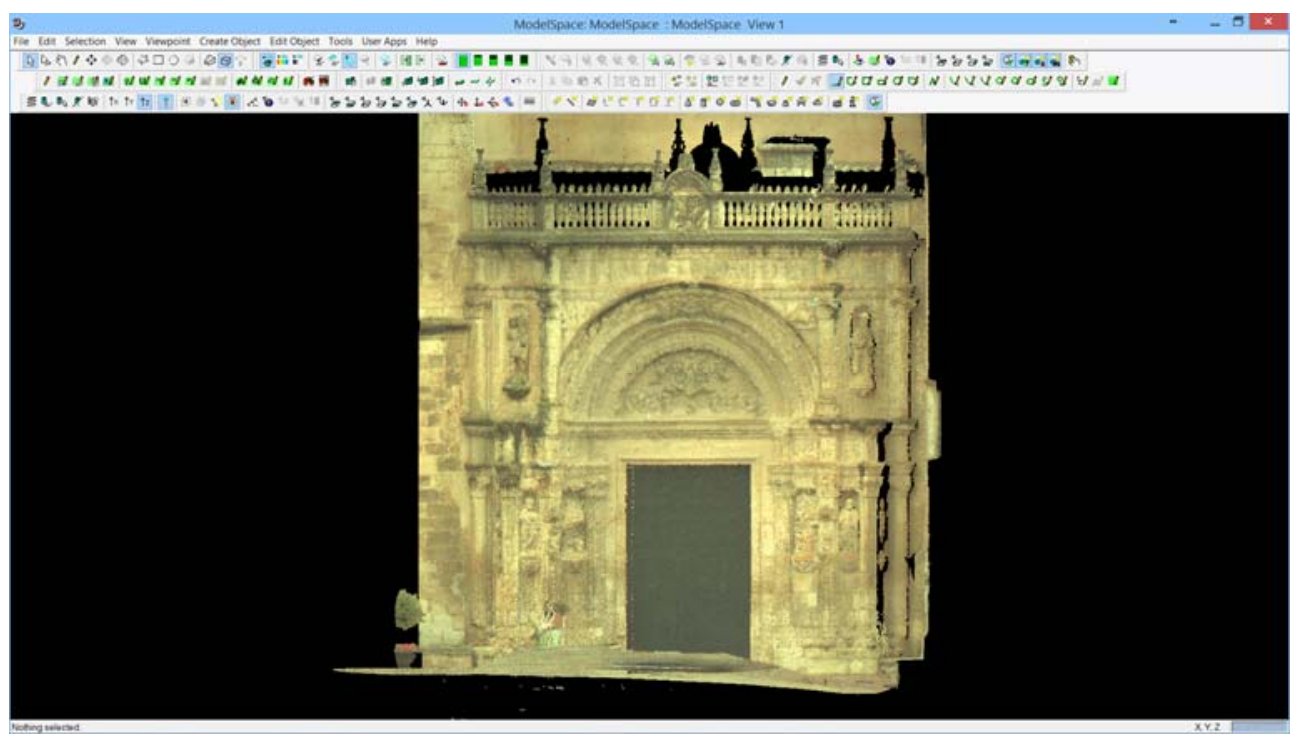

Figure 1: Detail of real chromatism of the cloud of points. 


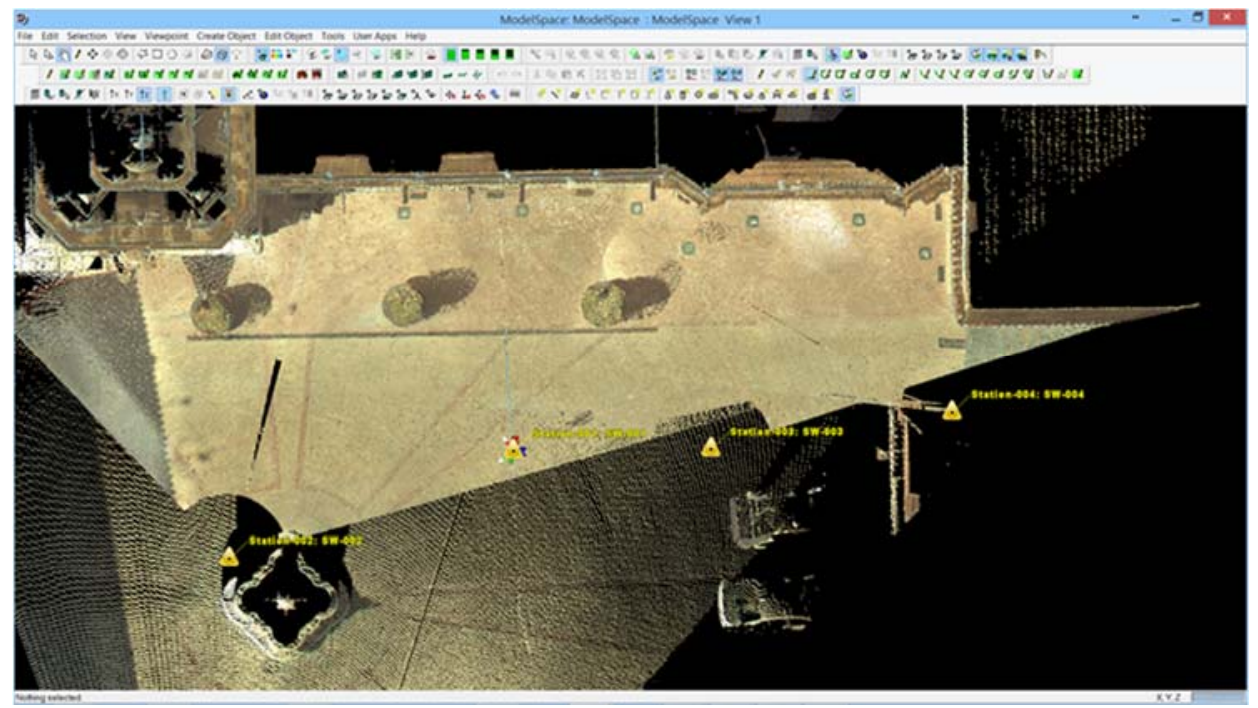

Figure 2: Third phase of data collection (March 29th, 2017).

\section{WORKFLOW TO GET THE POINT CLOUD FOR THE INTERPRETATION OF DATA}

For the recording and processing of the work we use the Leica Cyclone 9.0.1 software, with which we will join the parking lots of each of the phases of the field work and do the cleaning and filtering of the point cloud.

In the results of the registration of the second phase of work, and that will be used to obtain the 3D mesh of the façade, the maximum error obtained between the different parking lots does not exceed $5 \mathrm{~mm}$, being an acceptable error (Fig. 3). Once the parking lots are united and after a process of cleaning and filtering the data, we export them in a *.pts file for its later modeling process.

To link this point cloud in both the Revit BIM environment and the 2D/3D environment of AutoCAD, the *.pts (from Leica Cyclone) extension transformation process is required, in the *.rcs format, using for this the Autodesk RECAP 360 software (Fig. 4).

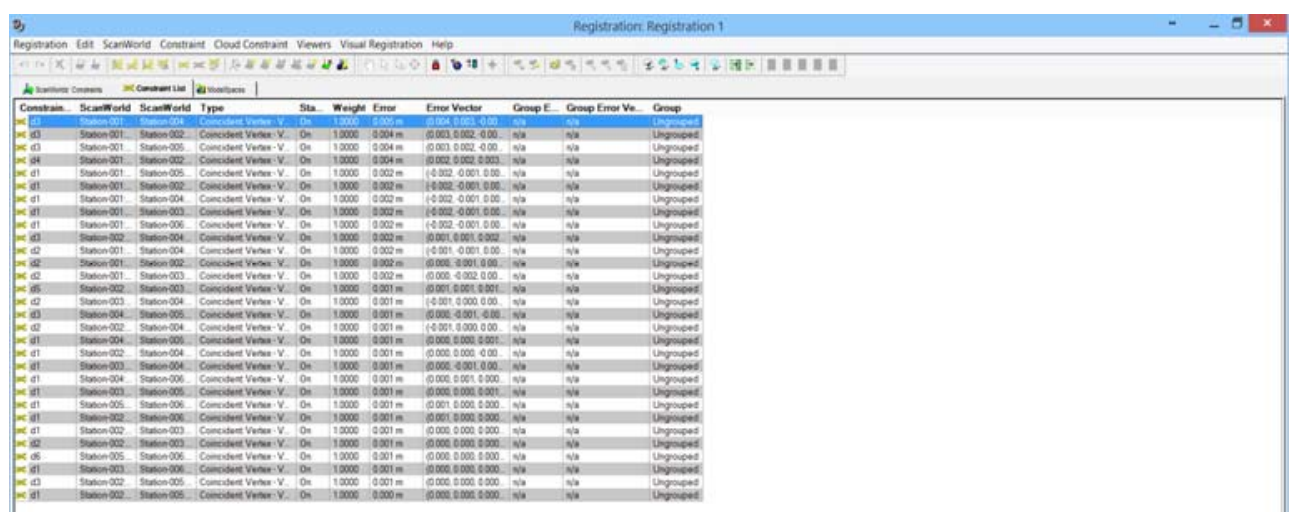

Figure 3: Data logging results. 


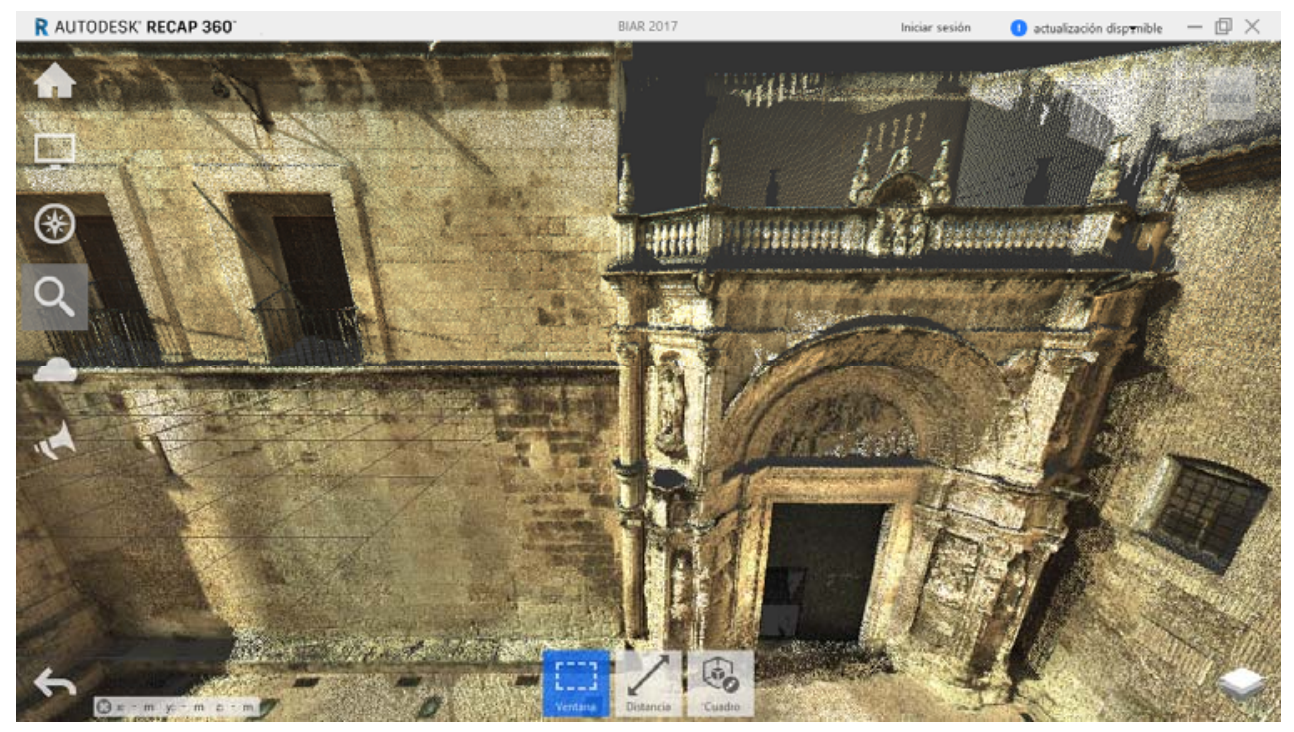

Figure 4: Cloud viewing points by 360 RECAP.

\section{THE MODELING PHASE}

For the modeling of the façade in $3 \mathrm{D}$, we used the data obtained in the second phase of the field work, using 3DReshaper software in its version 17,0,04,24386. This program is based on the triangulation of points to generate surfaces, which can later be applied an external texture map. For this we import the *.pts file of the point cloud, following two steps to generate the mesh. The first one is to generate a surface without holes. For this we chose the tool of the program "3D Mesh" and "Normal Sampling". This command causes the program to choose the points that most closely approximate the reality of the scanned object.

In this first step it is convenient that the distance between points to choose is high, reason why we opted for a distance of $0.2 \mathrm{~m}$. The program automatically sets a maximum size of the triangle with which the detected holes will be filled, which will be 3 times greater than the distance between points. With this we get a very large first mesh, but without holes.

With the second step a refinement of this mesh is achieved, using the tool "Refining error of deviation" and the command "Interpolate new points". With this the program generates new points inside the mesh that do not belong to the original cloud but that are necessary to obtain an optimal result.

In this case we choose the option "Refined Interpolation of evenly spaced points" with a maximum spacing of $0.02 \mathrm{~m}$. Points are added so that the distance between two neighboring vertices is not greater than $2 \mathrm{~cm}$, so that the surface fits to the cloud as much as possible and in no case deviates by more than $1 \mathrm{~mm}$.

3DReshaper allows us to export the data in multiple formats, being *.stl and *.obj the most usual to later work with other modeling programs.

\section{INTEGRATION IN BIM}

For the working phase in BIM, we use the software Revit in its version 2017. For the import of the mesh generated from the façade to BIM, we must export it previously in file *.dxf that allows 3DReshaper and insert it in our model of Revit. For this we can import it as "Model In-Place" within architectural components (Fig. 5). 
Once here, we have the option of inserting it as "Generic Models" or "Mass" (Fig. 6).

The other option to insert the mesh, would be through the option "Massing \& Site" and the "In-Place Mass" option (Fig. 7).

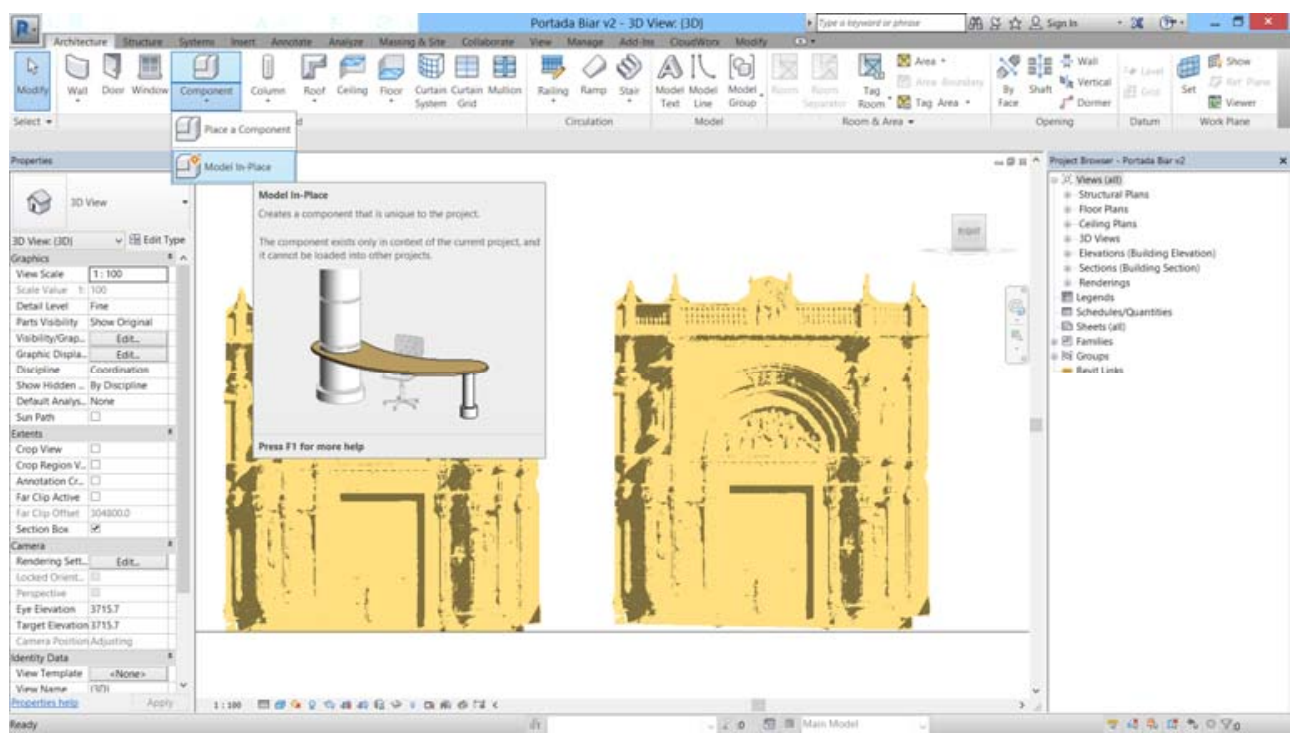

Figure 5: Detail of the "Model in Place" tool by Revit.

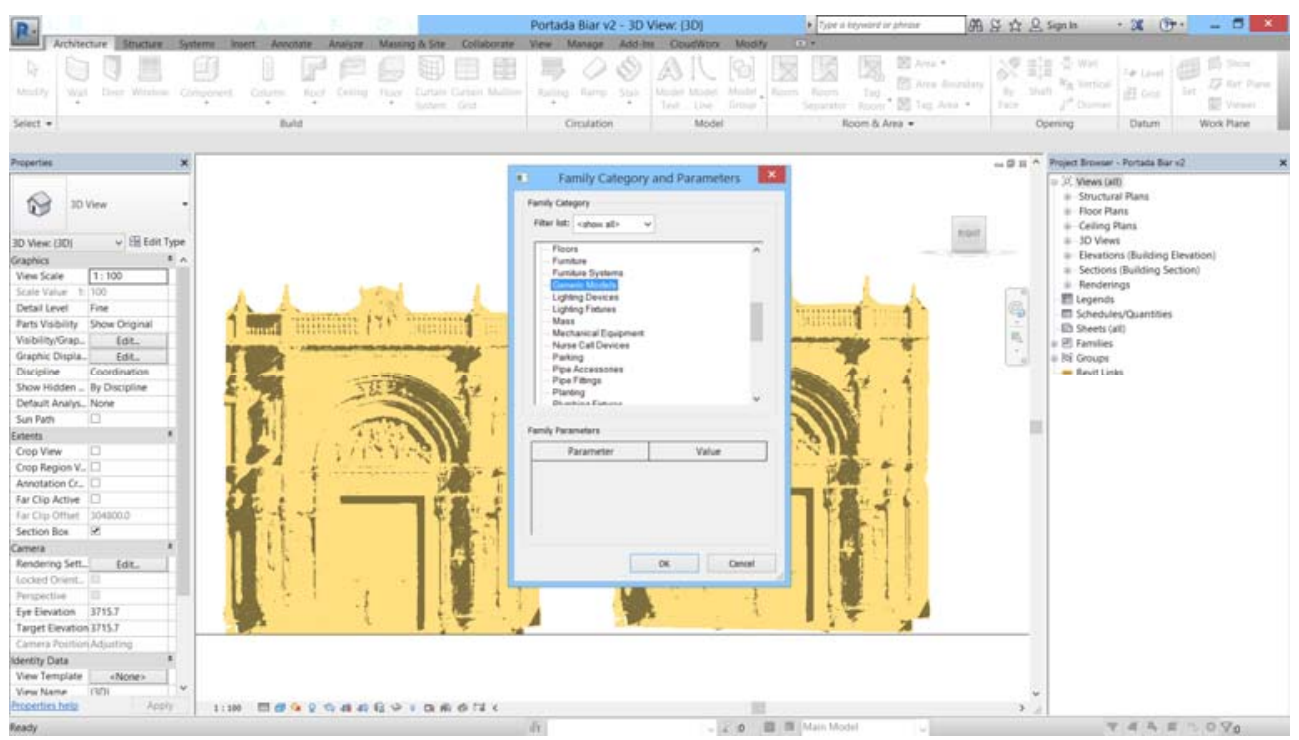

Figure 6: Detail of the "Generic Models" tool by Revit. 


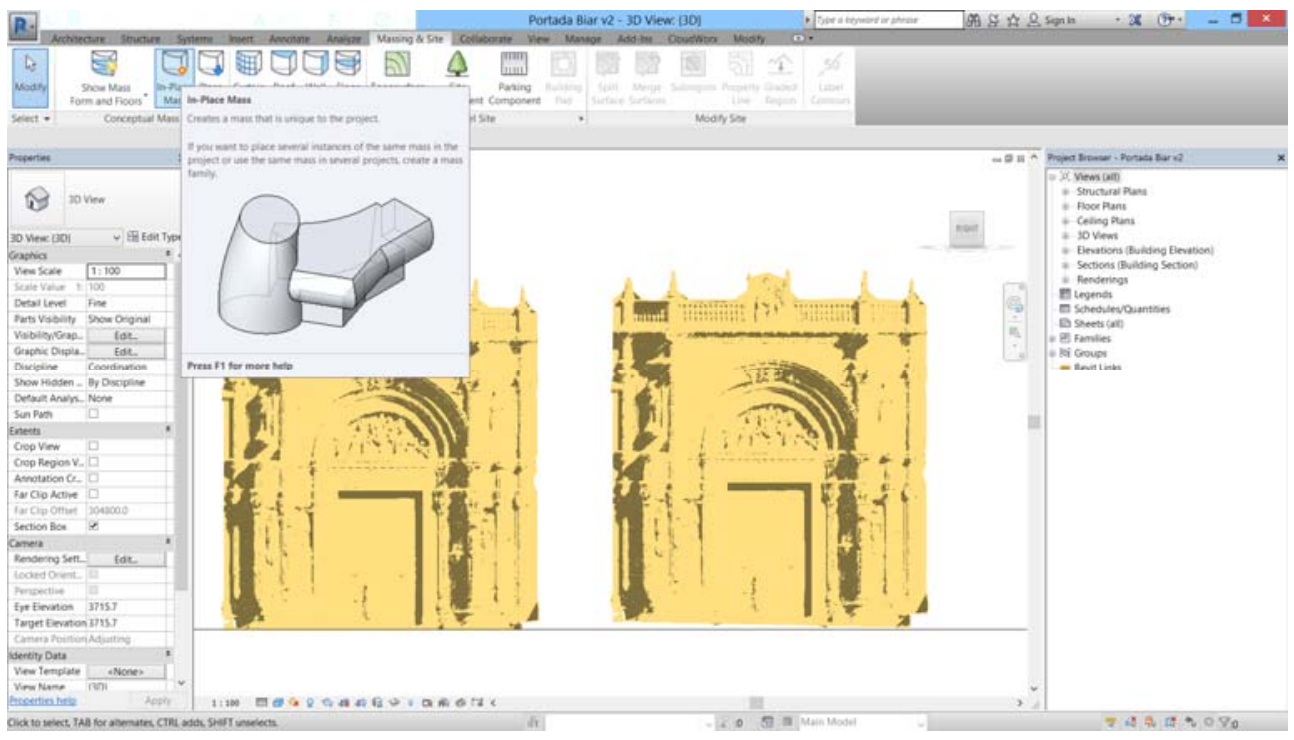

Figure 7: Detail of the "In-Place Mass" tool by Revit.

Either of the two options that have been used serves to integrally model the element, as a single family, without distinction of all its architectural and constructive composition. For this second phase must take into account the decomposition of the same in as many elements as required, creating independent meshes for each of the architectural elements and for each of the families that we want to identify and model (Fig. 8). It is highly recommended to generate the model taking into account the constructive process, in this case not only the constructive but also the possible future maintenance and conservation interventions.

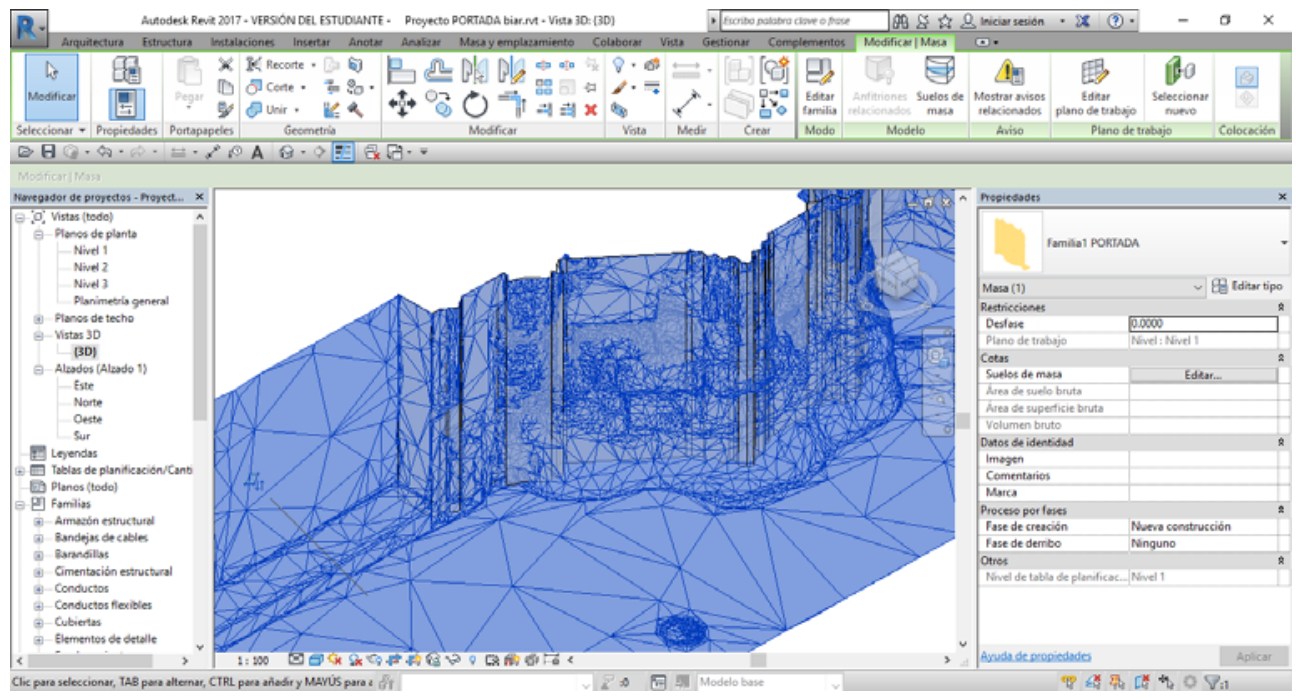

Figure 8: Viewing 3D mesh at the bottom of the main front. 
In this case we have worked on one of the sides of the main front, namely the right side of the zone of the base and has been modeled creating a new family as conceptual mass from a polyline generated in a section of the cloud of points and linked as a CAD file. Once loaded to the architectural project it is only necessary to generate the wall as an element from "wall by face" (Fig. 9), assigning a type of wall previously established, even assigning the actual material that is composed with all its attributes (Figs 10 and 11).

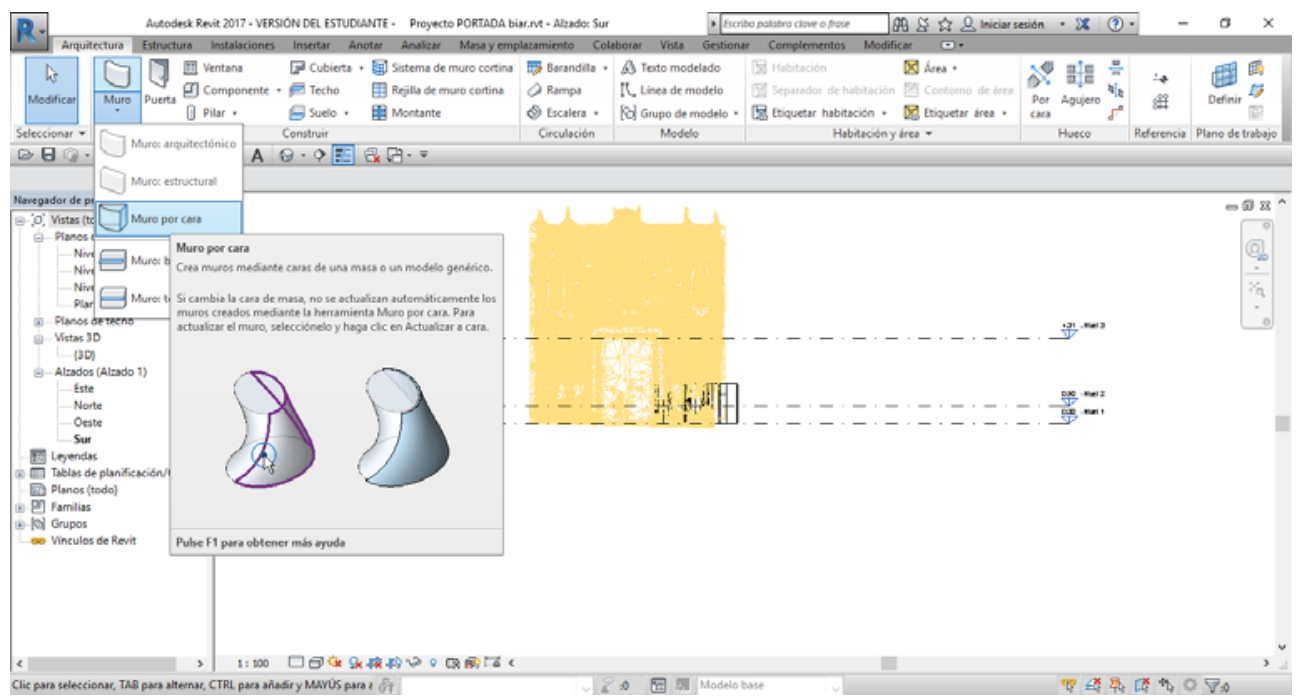

Figure 9: Detail of the "Wall by face" tool by Revit.

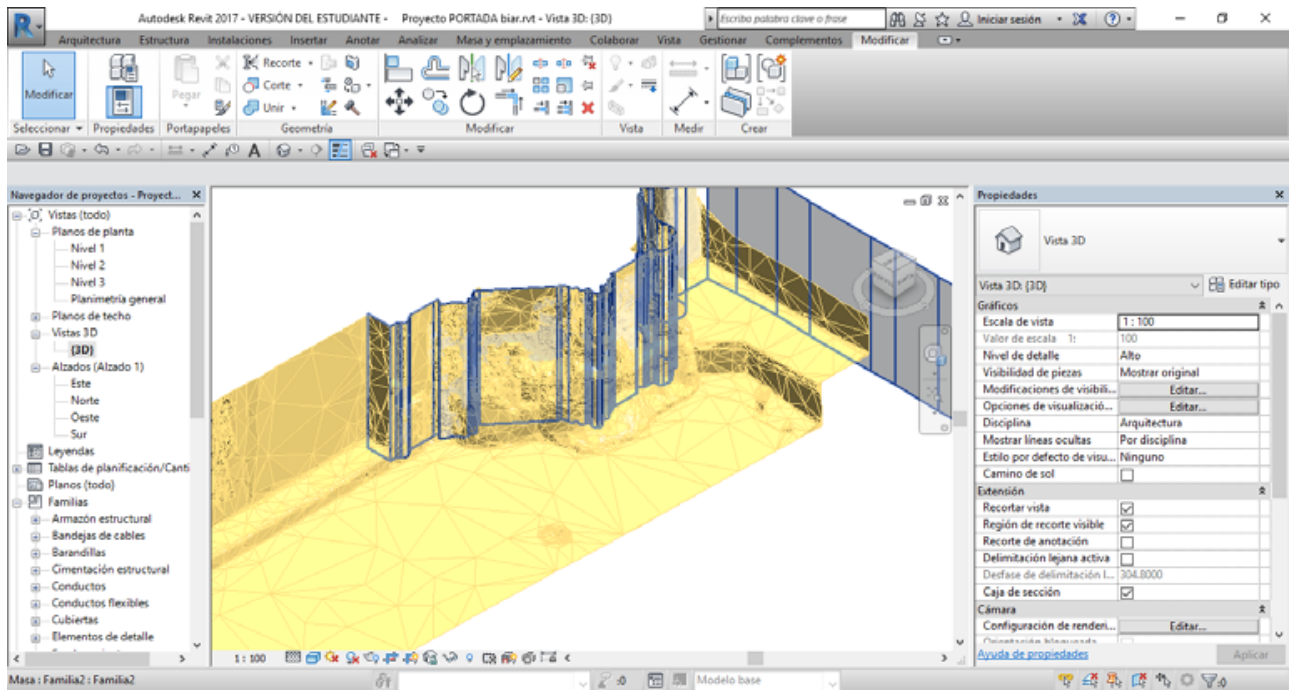

Figure 10: Generation family masonry wall split down the main front. 


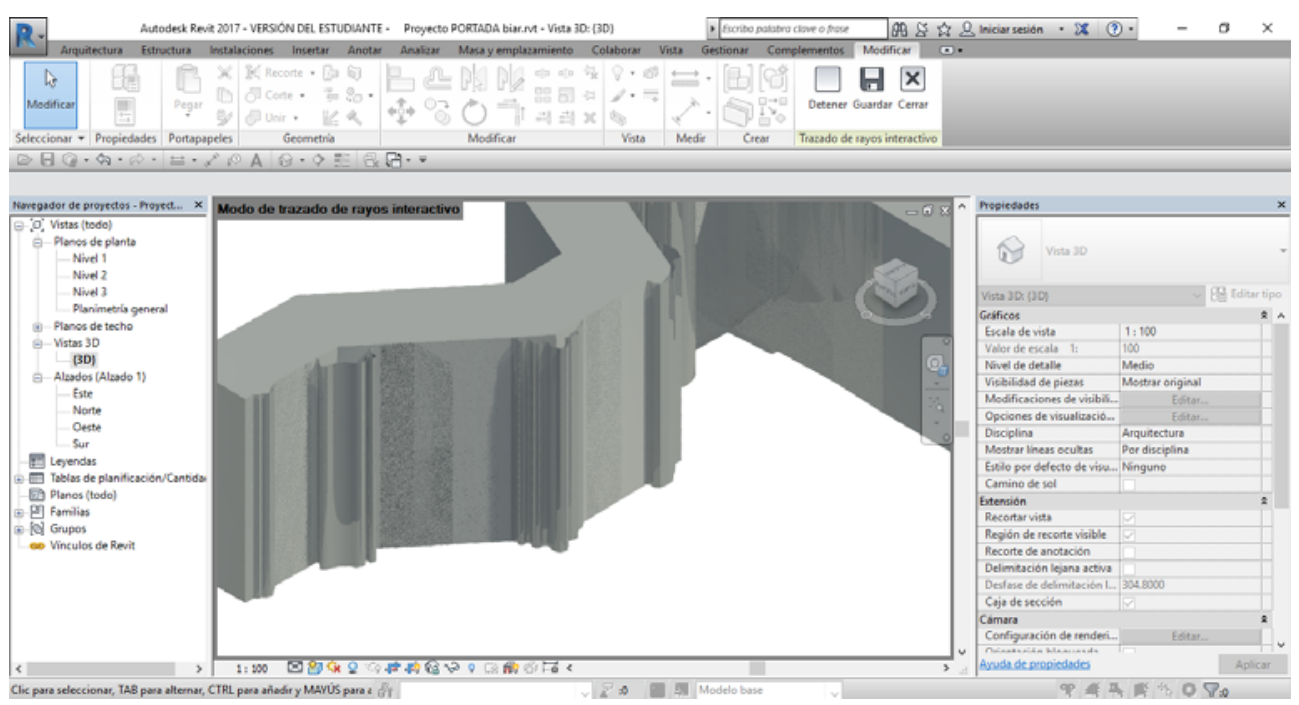

Figure 11: Final aspect of modeling the wall.

\section{CONCLUSIONS}

One of the first phases in the management of the built heritage is to know its real state, and this prior knowledge always leads to its representation and its graphic survey. Nowadays, fortunately, there are tools that allow us to perform with an important level of precision and in virtual and three-dimensional, for example, by means of the terrestrial laser scanner and others specialized software.

The difficult thing is to decide what tools can generate this information and what the workflow is advisable in order to get the desired results and in the most efficient way possible (Fig. 12).

In this sense and with the experience of this study we have come to obtain the best results following the workflow that has been described during this document and that of the accompanying scheme.

The biggest drawback we have encountered has been when modeling in the BIM environment since there are no specific routines to be able to incorporate $3 \mathrm{D}$ meshes generated from the point clouds, but it has had to be incorporated in form of new families and types each of the elements that make up the element to study, the building façade.

It is necessary, also to be able to investigate more about the insertion of $3 \mathrm{D}$ meshes in tools like Revit and the possibility that they can be directly linked in the conceptual mass generation or families, since they would optimize the working times. Since in our case we have had to help with previous transformations and work in the AutoCAD environment and then link it to Revit. It is also possible to model from the point cloud, but what is intended is to be able to optimize working times and final results

Finally, it is highly recommended that the BIM environment is also developed and focused for the management of the built heritage and not only for the new building, in view of the real need that professionals have to preserve and maintain our architecture already built. 


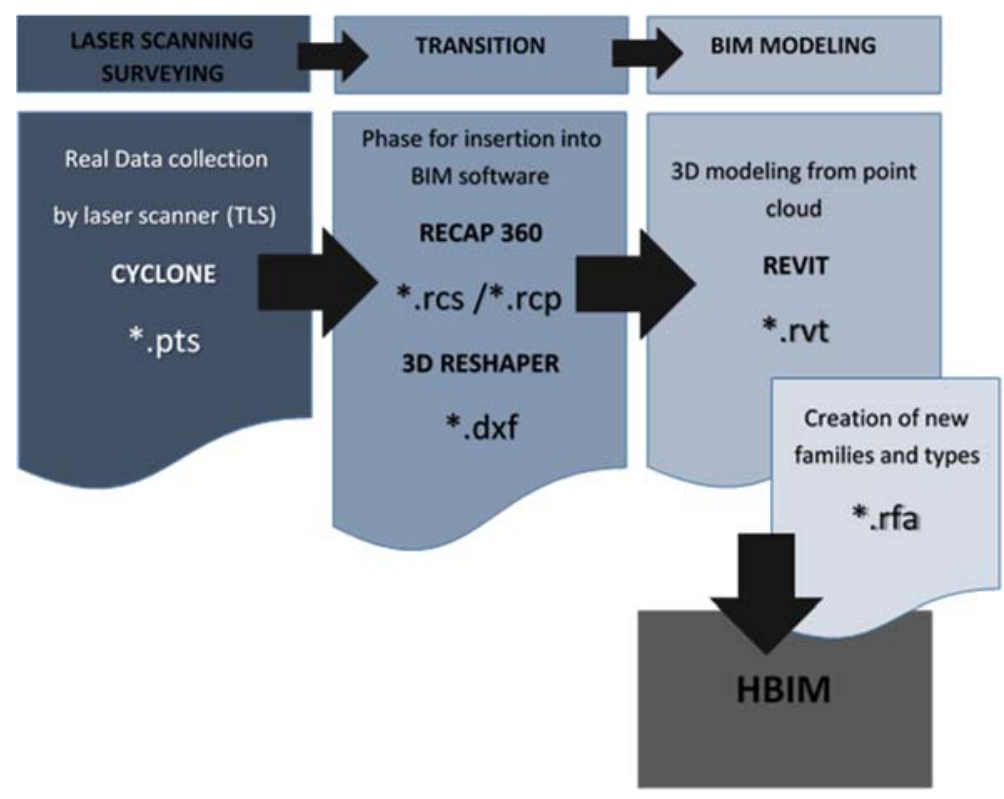

Figure 12: Workflow used in this study.

\section{REFERENCES}

[1] Hichri, N., Stefani, C., de Luca, L. \& Veron, P., Review of the "as-buit BIM" approaches, 2013.

[2] Hichri, N., Stefani, C., de Luca, L., Veron, P. \& Hamon, G., From point cloud to BIM: A survey of existing approaches. IV International CIPA Symposium, France, Proceedings of the XXIV International CIPA Symposium, 2013.

[3] Tommasi, C., Achille, C. \& Fassi, F., From point cloud to BIM: A modelling challenge in the cultural heritage field. The International Archives of the Photogrammetry, Remote Sensing and Spatial Information Sciences, 41(B5), 2016.

[4] Quattrini, R., Malinverni, E., Clini, P., Nespeca, R. \& Orlietti, E., From TLS to HBIM. high quality semantically-aware $3 \mathrm{D}$ modeling of complex architecture. The International Archives of Photogrammetry, Remote Sensing and Spatial Information Sciences, 40(5), p. 367, 2015.

[5] Brumana, R., Oreni, D., Raimondi, A., Georgopoulos, A. \& Bregianni, A., From survey to HBIM for documentation, dissemination and management of built heritage: The case study of St. Maria in Scaria d'Intelvi. Digital Heritage International Congress (DigitalHeritage), 1, pp. 497-504, 2013.

[6] Chiabrando, F., Sammartano, G. \& Spanò, A., Historical buildings models and their handling via 3D survey: From points clouds to user-oriented HBIM. International Archives of the Photogrammetry, Remote Sensing and Spatial Information Sciences, 41, pp. 633-640, 2016. 